NOTE

\title{
Synechocystis MCCB 114 and 115 as putative probionts for Penaeus monodon post-larvae
}

\author{
R. Preetha ${ }^{1}$, N. S. Jayaprakash ${ }^{1,2}$, I. S. Bright Singh ${ }^{1, *}$ \\ National Centre for Aquatic Animal Health, Cochin University of Science and Technology, Lakeside Campus, \\ Fine Arts Avenue, Cochin 682016, India \\ ${ }^{2}$ Present address: Centre for Bioseparation Technology, Vellore Institute of Technology, Vellore 632014, Tamil Nadu, India
}

\begin{abstract}
Synechocystis MCCB 114 and 115 were segregated as putative probionts for shrimp larvae from a collection of 54 cyanobacterial cultures enriched from seawater. On feeding Penaeus monodon post-larvae with the cyanobacteria, the generic diversity of the intestinal bacterial flora could be enhanced with substantial reduction or total absence of Vibrio spp. A significant difference $(p<0.001)$ in the percent survival of batches of post-larvae fed on the cyanobacterial cultures was observed and, on repeated challenge with $V$. harveyi, the relative percent survival of those batches of larvae fed on Synechocystis MCCB 114 and 115 was significantly higher. The Synechocystis MCCB 114 and 115 cultures were found to contain high levels of protein (34 to $43 \%$ ), in addition to carotenoids.
\end{abstract}

KEY WORDS: Probiotic - Vibriosis · Antagonism - Vibrio - Aquaculture ' Synechocystis · Cyanobacteria $\cdot$ Shrimp

Resale or republication not permitted without written consent of the publisher

\section{INTRODUCTION}

Probiotics are defined as live microbial adjuncts that have beneficial effects on their host by modifying the host-associated or ambient microbial community, ensuring improved use of feed by enhancing its nutritional value, host's response to disease, or by improving the quality of the host's ambient environment (Verschuere et al. 2000). Cyanobacteria (blue-green algae) have not yet been suggested as candidate probiotics in aquaculture. However, marine cyanobacteria in particular have been in focus for quite some time as a potential source of antagonistic compounds (Pergament \& Carmeli 1994, Mundt et al. 2001). The secretion of antimicrobial substances is an important part of the competition process in the natural environment, having a beneficial effect on the host by modifying the host-associated ambient microbial community (Verschuere et al. 2000). Cyanobacteria are a good source of nutrients (Morist et al. 2001) and their cellular contents may promote the growth of gut bacteria and accelerate the process of nutrient absorption. Considering the above, the present study was undertaken to screen and segregate specific cyanobacterial cultures from the marine environment as putative probiotics to be used in shrimp hatcheries. This selection was based on (1) in vitro antagonism, (2) ability to regulate the intestinal bacterial flora, and (3) enhancement of the survival of Penaeus monodon post-larvae after challenge with Vibrio harveyi subsequent to being fed the cyanobacteria.

\section{MATERIALS AND METHODS}

Cyanobacterial cultures. Water samples $(n=9)$ were collected from surface waters of the sea surrounding Vypeen Island $\left(09^{\circ} 58^{\prime} \mathrm{N}, 76^{\circ} 17^{\prime} \mathrm{E}\right)$ using a Niskin 
water sampler (General Oceanics). Samples were transferred aseptically to sterile glass bottles of $100 \mathrm{ml}$ capacity, and brought to the laboratory in an ice chest within $2 \mathrm{~h}_{i} 1 \mathrm{ml}$ of each sample was then inoculated in each of 6 enrichment media: BG-11, ASN-111 and MN (Rippka et al. 1979), modified Chu-11 (Cohen 1975), Allen and Nelson's medium (Allen \& Nelson 1910) and Walne's medium (Walne 1974), all prepared in sea water. Samples were incubated at $28 \pm 0.4^{\circ} \mathrm{C}$ under $12 \mathrm{~h}$ illumination at $40 \mu \mathrm{E} \mathrm{m} \mathrm{m}^{-2} \mathrm{~s}^{-1}$, provided by cool fluorescent lamps (Philips), resulting in 54 cyanobacterial enrichment cultures.

Screening. Primary and secondary screening were accomplished by evaluating the antimicrobial activity of cell-free culture supernatants (Sample 1), cell lysate after sonication (Sample 2), cell debris separated by centrifugation of the sonicated cells (Sample 3) and intact washed cells (Sample 4) on a panel of 14 species of Vibrio ( $V$. alginolyticus, $V$. harveyi, $V$. splendidus, $V$. parahaemolyticus, $V$. vulnificus, $V$. orientalis, $V$. cincinnatiensis, $V$. marinus, $V$. mimicus, $V$. proteolyticus, $V$. mediterranei, $V$. fluvialis, $V$. proteolyticus and $V$. cholerae) via the standard disc diffusion method (Jayaprakash et al. 2005). The Vibrio spp. used were previously isolated from shrimp larval rearing systems, characterized following Alsina \& Blanch (1994), and maintained at the National Centre for Aquatic Animal Health (NCAAH) as part of its culture collection.

The effect of cyanobacterial cultures (segregated during the secondary screening) on the intestinal bacterial flora of Penaeus monodon post-larvae (PL-20; 0.1 to $0.15 \mathrm{~g}$ ) was tested by administering them with commercial feed (Higashimaru India) on a daily basis. The feed was coated with cyanobacteria at the time of feeding using 'Bindex' (Matrix Vet Formulations) at 1:1 ratio, dried in a desiccator at room temperature $(28 \pm$ $1^{\circ} \mathrm{C}$ ) for $2 \mathrm{~h}$, and fed ad libitum to P. monodon for $20 \mathrm{~d}$. The control tanks were maintained with normal feed. The PL-20 ( $\mathrm{n}=50)$ used for the experiment were maintained in duplicate fibreglass containers with $25 \mathrm{l}$ sea water $(30 \mathrm{ppt}) . \mathrm{NH}_{4}{ }^{+}-\mathrm{N}$ and $\mathrm{NO}_{2}{ }^{-}-\mathrm{N}$ of the rearing water were measured following Strickland \& Parson (1968), and maintained below 0.1 and 1 ppm, respectively, through water exchange.

Every $5 \mathrm{~d}, 5$ post-larvae each were sampled from each tank, disinfected with sodium hypochlorite (25 ppm available chlorine) for $15 \mathrm{~min}$, repeatedly washed in sterile seawater, macerated in $1 \mathrm{ml}$ sterile seawater diluent (25 ppt) using glass homogenizers, serially diluted, and inoculated onto ZoBell's Marine agar 2216E plates (Hi Media). Water samples from each tank were also plated after serial dilution in the same manner. After $7 \mathrm{~d}$ of incubation, colonies were isolated at random onto ZoBell's agar slants, and identified to genera following Oliver (1982) and
Alsina \& Blanch (1994). Generic diversity indices (Shannon-Wiener's diversity index, $H^{\prime}$ ) were then determined (Pielio 1966).

Shrimp survival following challenge with Vibrio harveyi. After $20 \mathrm{~d}$ of feeding, the survival of postlarvae was determined and remaining animals were challenged with $V$. harveyi MCCB 111 grown on ZoBell's marine agar 2216E plates supplemented with prawn muscle extract (Singh \& Philip 1993). The $V$. harveyi culture, harvested in sterile seawater, was coated onto feed using Bindex to obtain $10^{9}$ cells $^{-1}$, and fed afresh at a dosage of $0.5 \mathrm{~g}$ per 50 shrimp twice a day (at 06:00 and 18:00 h). From the following day, feeding with the diet coated with cyanobacterial cultures was resumed. The post-larvae were observed for mortality and, after $10 \mathrm{~d}$, those that survived the first challenge were re-challenged with $V$. harveyi in the same manner. The surface of any moribund animals was disinfected, macerated, serially diluted and plated as described above. Luminescent colonies were isolated after a $24 \mathrm{~h}$ incubation, purified and identified as $V$. harveyi. The above experiment was repeated and the data analyzed statistically using ANOVA, and the relative percentage survival (RPS) was calculated according to Gram et al. (1999).

Based on the results, 2 cyanobacterial cultures (C-51 and C-54) found associated with significantly higher RPS during the challenges were segregated and identified to genera based on micro-morphology as described by Herdman et al. (2001) and subjected to further investigation.

Growth phase vs. antagonistic activity of cyanobacterial cultures. To determine the phase of growth of the cyanobacterial cultures at which maximum antiVibrio activity was exhibited, the cultures were inoculated in the above media and incubated until the stationary phase. During this period, aliquots of 2 to $4 \mathrm{ml}$ from each culture were centrifuged at $10000 \times g$ at $4{ }^{\circ} \mathrm{C}$ for 15 min every $3 d$, and the anti-Vibrio activity of the supernatant determined via standard disc diffusion using selected isolates of Vibrio spp. The media and the stage/phase at which each culture exhibited maximum activity were recorded.

Biochemical analysis. The cyanobacterial cultures were harvested by centrifugation at $10000 \times g$ for $15 \mathrm{~min}$ at $4^{\circ} \mathrm{C}$, washed repeatedly in saline $(0.85 \%$ $\mathrm{NaCl}$ ), and dried in a vacuum desiccator at room temperature $\left(28 \pm 0.5^{\circ} \mathrm{C}\right)$ to constant weight. The dried cells were powdered using glass homogenizers and analysed for total protein (Bradford 1976), carbohydrates (Hedge 1962) and lipids (Barnes \& Blachstock 1973). Chlorophyll content (APHA 1995), carotenoids (Anonymous 1998) and water-soluble pigments such as C-phycocyanin, allophycocyanin and phycoerythrin were also determined (Becker 1994). 
Table 1. Penaeus monodon. Shannon-Wiener diversity index $\left(H^{\prime}\right)$ of microbial diversity in the intestines of post-larvae and rearing water after administration of the cyanobacteria-coated feed

\begin{tabular}{|c|c|c|c|c|c|c|c|c|}
\hline & \multicolumn{7}{|c|}{ Experimental diet with cyanobacterial culture } & \multirow{2}{*}{$\begin{array}{l}\text { Control } \\
\text { feed }\end{array}$} \\
\hline & C- 44 & C-45 & C- -48 & C-50 & C-51 & C-53 & C-54 & \\
\hline Water & $0.64-0.69$ & $0.32-1.24$ & $0.59-1.03$ & $0.69-1.04$ & $0.686-0.693$ & $0.685-0.693$ & $1-1.56$ & $0.87-1.04$ \\
\hline
\end{tabular}

Table 2. Penaeus monodon. Average percentage survival of post-larvae fed with cyanobacteria before challenge, and relative percentage survival (RPS) after challenge with Vibrio harveyi

\begin{tabular}{|c|c|c|c|c|c|c|c|c|}
\hline & \multicolumn{7}{|c|}{ Experimental diet with cyanobacterial culture } & \multirow{2}{*}{ Control } \\
\hline & $\mathrm{C}-44$ & C-45 & C -48 & C-50 & C -51 & C-53 & C-54 & \\
\hline $\begin{array}{l}\text { Before } \\
\text { challenge }\end{array}$ & $83.86 \pm 0.26$ & $90.55 \pm 0.21$ & $89.25 \pm 0.22$ & $91.5 \pm 0.2$ & $96.77 \pm 0.13$ & $75.5 \pm 0.3$ & $98.94 \pm 0.07$ & $76.6 \pm 0.3$ \\
\hline $\begin{array}{l}\text { RPS after } \\
\text { 1st challenge }\end{array}$ & $23.5 \pm 1.96$ & $29.4 \pm 2.3$ & $23.5 \pm 1.86$ & $47.1 \pm 2.42$ & $82.4 \pm 1.82$ & $5.9 \pm 3.24$ & $70.6 \pm 2.64$ & \\
\hline $\begin{array}{l}\text { RPS after } \\
\text { 2nd challenge }\end{array}$ & $18.75 \pm 2.12$ & $37.04 \pm 2.6$ & Nil & $48 \pm 2.82$ & $59.3 \pm 2.2$ & $18.75 \pm 2.6$ & $74.1 \pm 2.0$ & \\
\hline
\end{tabular}

\section{RESULTS}

Out of 54 cyanobacterial cultures, 52 showed antagonism to at least 1 isolate of Vibrio spp. and, from this group, 7 cyanobacterial cultures (C-44, C-45, C-48, C-50, C-51, C-53 and C-54) could be segregated in such a way that antibacterial activity could be detected against all the Vibrio spp. isolates. Whenever antagonistic activity in the culture supernatant was detected (Sample 1), it could also be demonstrated in the cell lysate (Samples 2 and 3). However, at times the activity was observed only in the cell lysate, not in the culture supernatant.

Vibrio spp. could not be recovered from the intestines of post-larvae fed with C-45, C-51, C-53 and C-54. However, heterotrophic bacterial flora in the intestines of post-larvae fed on the experimental diets with cyanobacterial cultures C-45, C-51 and C-54 exhibited comparatively higher generic diversity indices (Table 1).

A significant difference $(p<0.001)$ in the percent survival of batches of post-larvae fed on different cyanobacterial cultures was observed. The least significant difference (LSD) at the $0.1 \%$ level was calculated in order to identify the significant treatments, and determined to be 1.1051. Administration of cyanobacteria C-45, C-48, C-50, C-51, C-53 and C-54 resulted in a significantly higher survival rate in the test group of post-larvae, which were apparently healthy and pigmented compared with the control. On repeated challenge with Vibrio harveyi, the RPS of the batches of larvae fed on C-51 and C-54 were significantly higher than those of all others (Table 2). Based on our observations, the cultures C-51 and C-54 were segregated
Table 3. Biochemical composition of Synechocystis C-51 and C-54

\begin{tabular}{|c|c|c|}
\hline & C-51 & C-54 \\
\hline Protein $\left(\mathrm{mg} 100 \mathrm{mg}^{-1}\right)$ & $34.74 \pm 2.92$ & $43.43 \pm 7.43$ \\
\hline Carbohydrate $\left(\mathrm{mg} 100 \mathrm{mg}^{-1}\right.$ ) & $22.82 \pm 5.76$ & $20.57 \pm 2.27$ \\
\hline Lipid (mg $100 \mathrm{mg}^{-1}$ ) & $33.18 \pm 12.23$ & $28.25 \pm 2.19$ \\
\hline Chlorophyll $a\left(\mu \mathrm{g} \mathrm{mg}^{-1}\right)$ & $6.89 \pm 1.83$ & $3.99 \pm 0.64$ \\
\hline Carotenoid $\left(\mu \mathrm{g} \mathrm{mg}^{-1}\right)$ & $0.85 \pm 0.13$ & $0.39 \pm 0.08$ \\
\hline Allophycocyanin (mg $100 \mathrm{mg}^{-1}$ ) & $4.48 \pm 1.62$ & $2.14 \pm 0.55$ \\
\hline C-phycocyanin (mg $100 \mathrm{mg}^{-1}$ ) & $1.26 \pm 0.39$ & $0.5 \pm 0.08$ \\
\hline Phycoerythrin (mg $100 \mathrm{mg}^{-1}$ ) & Nil & Nil \\
\hline
\end{tabular}

as the putative probionts for shrimp larval rearing systems.

Synechocystis C-51 exhibited antagonistic activity in Walne's medium during the log phase, attaining a maximum at the end of the phase. However, maximum antagonistic activity of Synechocystis C-54 in ASN-111 was observed during the stationary phase. For generating biomass under the experimental conditions, the media Chu-11 and BG-11 were found to be most suitable for C-51 and C-54, respectively.

Total proteins, carbohydrates, lipids, chlorophyll $a_{\text {, }}$ carotenoid allophycocyanin, C-phycocyanin and phycoerythrin content of C-51 and C-54 are given in Table 3.

\section{DISCUSSION}

Over the years, application of probiotics in aquaculture has gained an impressive momentum, which is focused on sustainability in the production process. Different groups of microorganisms such as Lacto- 
bacillus spp., Bacillus spp., Pseudomonas spp., Micrococcus spp., certain strains of Vibrio, yeast and microalgae have been reported as putative probiotics. (Gomez-Gil et al. 2000, Verschuere et al. 2000, Irianto \& Austin 2002). Several of these microorganisms have been identified as possessing antagonistic properties and have been designated as 'biocontrol agents' (Verschuere et al. 2000). It is in this context that the present study was undertaken to screen cyanobacteria enriched from the marine environment to be used as candidate probiotics in shrimp larval production systems. More than $96 \%$ of the cyanobacterial cultures examined in this study exhibited in vitro antagonism to at least 1 Vibrio isolate.

The anti-Vibrio property of the cyanobacteria investigated here derived from both extracellular and intracellular sources, strengthening the argument of Chetsumon et al. (1995) that bioactive molecules are initially accumulated intracellularly. If so, the cells might be used as probiotics to regulate the intestinal bacterial flora favorable to shrimp post-larvae through antagonism.

These cultures showed antagonism against known aquaculture pathogens such as Vibrio harveyi and $V$. parahaemolyticus (Karunasagar et al. 1994, Jayaprakash et al. 2005). It is postulated that the survival of those Penaeus monodon post-larvae fed the Synechocystis C-51 and C-54 and subjected to repeated challenge with $V$. harveyi may be a result of an antagonistic probiotic effect. Moreover, the higher protein content of Synechocystis C-51 and C-54 (equivalent to that of commercial feed) and the presence of carotenoids also make the cultures ideal feed additives, which would contribute to the weight gain and colouration of shrimp post-larvae. During this study, those post-larvae fed with Synechocystis were found to be visibly more pigmented than the control animals. Furthermore, as suggested by Becker (1994), phycobiliproteins such as C-phychocyanin and allophycocyanin from different species of cyanobacteria have growth-promoting activities and immunostimulatory properties as well.

In addition to coating feed particles with the cyanobacterial cells, the Synechocystis C-51 and C-54 can be bioaccumulated in rotifers (Sakamoto et al. 1996) and fed to crustacean larvae. Additionally, the cyanobacterial cultures as such or the washed cells can be added directly to the larval rearing system.

When the cyanobacterial cultures were fed to shrimp post-larvae, the generic diversity index of the intestinal heterotrophic bacterial flora increased along with either a concomitant reduction in or total absence of Vibrio spp. in those individuals fed with Synechocystis C-51 and C-54. This is in accordance with the observations of Rico-Mora et al. (1998), who reported that a bacterial strain associated with Skeletonema costatum had prevented the establishment of $V$. alginolyticus in crustacean larvae.

In conclusion, this study suggested that Synechocystis $\mathrm{C}-51$ and $\mathrm{C}-54$ could be considered as candidate probiotic organisms suitable for shrimp culture. These cyanobacterial cultures form part of the microbial culture collection of the NCAAH, Cochin University of Science and Technology, and are catalogued as Synechocystis MCCB 114 and Synechocystis 115.

Acknowledgements. This research was funded by the Department of Ocean Development, Government of India and Cochin University of Science and Technology. R.P. thanks the Department of Ocean Development and Cochin University of Science and Technology for a fellowship. We are thankful to Prof. R. Reed from the Division of Biomedical Sciences, Northumbria University for editing a previous version of the manuscript.

\section{LITERATURE CITED}

Allen EJ, Nelson EW (1910) On the artificial cultures of marine planktonic organisms. J Mar Biol Assoc UK 8:421

Alsina M, Blanch AR (1994) A set of keys for biochemical identification of environmental Vibrio species. J Appl Bacteriol 76:79-85

Anonymous (1998) GIS based information system for critical coastal habitats in India. In: Manual on methodology for biological parameters. Integrated Coastal and Marine Area Management Project Directorate, Department of Ocean Development, Channai

APHA (American Public Health Association) (1995) Standard methods for the examination of water and waste water, 19th edn. American Public Health Association, Washington, DC

Barnes H, Blachstock J (1973) Estimation of lipids in marine animals and tissues: detailed investigation of the sulphophosphovanillin method for 'total lipids'. Mar Biol Ecol 2:103-118

Becker EW (1994) Measurement of algal growth. In: Baddiley J, Carey NH, Higgins IJ, Potter WG (eds) Microalgae, biotechnology and microbiology. Cambridge University Press, Cambridge, p 59-60

Bradford MM (1976) A rapid and sensitive method for the quantification of microgram quantity of proteins utilizing the principle of protein dye binding. Ann Biochem 72: $248-254$

Chetsumon A, Maeda I, Umeda F, Yagi K, Miura Y, Mizoyuchi (1995) Continuous antibiotic production by an immobilized cyanobacterium in a seaweed-type bioreactor. J Appl Phycol 7:135-139

Cohen Y (1975) Dynamics of prokariotic photosynthetic communities of the solar lake. PhD thesis, Herew University, Jerusalem

Gomez-Gil B, Roque A, Turnbull J (2000) The use and selection of probiotic bacteria for use in culture of larval aquatic organisms. Aquaculture 191:259-270

Gram L, Melchiorsen J, Spanggaard B, Huber I, Nielsen TF (1999) Inhibition of Vibrio anguillarum by Pseudomonas flurescens $\mathrm{AH} 2$, a possible probiotic treatment of fish. Appl Environ Microbiol 65:969-973

Hedge JE (1962) Analysis and preparation of sugars. In: 
Whistler RL, Wolfrom ML (eds) Methods in carbohydrate chemistry. Academic Press, New York, p 335-343

Herdman M, Castenholz RW, Itman I, Waterbury JB, Rippka R (2001) Phylum BX cyanobacteria, subsection 1. In: Garrity GM, Boone DR, Castenholz RW (eds) Bergey's manual of systematic bacteriology, Vol 1. Williams \& Wilkins, Baltimore, MD, p 493-514

Irianto A, Austin B (2002) Probiotics in aquaculture. J Fish Dis 25:633-642

Jayaprakash NS, Pai SS, Anas A, Preetha R, Philip R, Bright Singh IS (2005) A marine bacterium, Micrococcus MCCB104, antagonistic to vibrios in prawn larval rearing systems. Dis Aquat Org 68:39-45

Karunasagar I, Pai R, Malathi GR, Karunasagar I (1994) Mass mortality of Penaeus monodon larvae due to antibiotic resistant Vibrio harveyi infection. Aquaculture 128: 203-209

Morist A, Montesinos JL, Cusido JA, Godia F (2001) Recovery and treatment of Spirulina platensis cultured in a continuous photobioreactor to be used as food. Proc Biochem 37:535-547

Mundt S, Kreitlow S, Nowotny A, Effmert U (2001) Biochemical and pharmacological investigation of selected cyanobacteria. Int J Hyg Environ Health 203:327-334

Oliver JD (1982) Taxonomic scheme for the identification of marine bacteria. Deep-Sea Res 297:95-798

Editorial responsibility: Timothy Flegel,

Bangkok, Thailand
Pergament I, Carmeli S (1994) Schizotrin A; a novel antimicrobial cyclic peptide from a cyanobacterium. Tetrahedron Lett 35:8473-8476

Pielio E (1966) The measurement of diversity in different types of biological collections. J Theor Biol 13:131-144

Rico-Mora R, Voltolina D, Villaescusa-Celaya JA (1998) Biological control of Vibrio alginolyticus in Skelitonema costatum (Bacillariophyceae). Aquacult Eng 19:1-6

Rippka R, Deruelles J, Waterbury JB, Herman M, Stanierr RY (1979) Generic assignments, strains, histories and properties of pure cultures of cyanobacteria. J Gen Microbiol 111:1-61

Sakamoto K, Okimasu E, Amemura A (1996) Isolation of a micro algae, Synechocystis sp. SY-4, potentially useful as a rotifer feed. J Ferment Bioeng 82:157-160

Singh ISB, Philip R (1993) Compartive efficiency of three media in isolating heterotrophic bacteria from larvae and larval rearing water of Macrobrachium rosenbergii. Indian J Microbiol 33:67-69

Strickland JDH, Parson TR (1968) A practical hand book of seawater analysis. Bull Fish Res Board Can 167:311-312

Verschuere L, Rombaut G, Sorgeloos P, Verstraete W (2000) Probiotic bacteria as biological control agents in aquaculture. Microbiol Mol Biol Rev 64:655-671

Walne PR (1974) Culture of bivalve mollusks, Vol 1. Fishing News Books, Farnham, p 1-173

Submitted: July 4, 2006; Accepted: December 7, 2006

Proofs received from author(s): February 24, 2007 